\title{
Urgences
}

\section{La décision}

\section{Huguette Marquis}

Numéro 2, 3e trimestre 1981

URI : https://id.erudit.org/iderudit/025026ar

DOI : https://doi.org/10.7202/025026ar

Aller au sommaire du numéro

Éditeur(s)

Urgences

ISSN

0226-9554 (imprimé)

1927-3924 (numérique)

Découvrir la revue

Citer ce document

Marquis, H. (1981). La décision. Urgences, (2), 37-45.

https://doi.org/10.7202/025026ar

Ce document est protégé par la loi sur le droit d'auteur. L'utilisation des services d'Érudit (y compris la reproduction) est assujettie à sa politique d'utilisation que vous pouvez consulter en ligne.

https://apropos.erudit.org/fr/usagers/politique-dutilisation/
Cet article est diffusé et préservé par Érudit.

Érudit est un consortium interuniversitaire sans but lucratif composé de l'Université de Montréal, l'Université Laval et l'Université du Québec à Montréal. Il a pour mission la promotion et la valorisation de la recherche. https://www.erudit.org/fr/ 
HUGUETTE MARQUIS

\section{La décision}


La femme porte la tasse de café froid à ses lèvres, en boit une petite gorgée, puis la repose doucement tout en promenant un regard perdu autour de la pièce. L'état alternatif d'abattement et d'excitation qui s'est emparé d'elle ce matin ne laisse pas de l'inquiéter. Il lui faut réagir, éviter que le flot de désespoir qui l'oppresse ne la submerge complètement. Elle reporte son attention sur ce qui l'entoure.

Cette pièce, comme elle la hait! En trente ans, trop peu de choses y ont changé. Son regard glisse sur l'évier démodé dans lequel traîne la vaisselle sale, les vieilles armoires à l'air triste, le papier peint, remplacé d'année en année par à peu près le même motif, le plancher de bois verni... Presque rien n'a changé, sauf.... elle-même.

Tournant la tête, elle contemple la cuisinière toute neuve, étincellante, étrangement déplacée dans un pareil décor. Elle repose à l'écart, tout au bout de la cuisine. Et pourtant! N'aurait-il pas été plus commode de la placer entre le réfrigérateur et l'armoire, comme elle en avait exprimé le désir. Cela n'aurait demandé, en fait, que de légères modifications. Mais "il" en avait décidé autrement. Que cela l'obligeât à accomplir ainsi une multitude de pas inutiles au cours d'une journée n'avait en rien modifié sa décision. Car ses décisions sont définitives. Et il n'y revient jamais... jamais. Son coeur se serre.

Son regard est attiré par le couvert dressé au bout de la table; il y repose depuis la veille au soir, intact. Elle détourne les yeux, soudain remplie d'angoisse. Où a-t-il encore passé la nuit? Pourquoi agit-il ainsi? Que lui a-t-elle donc fait? Car, mème en repassant inlassablement toute la journée d'hier dans sa tête, rien, qui eût pu expliquer son geste, rien ne s'est produit. 
La femme lève ses épaules un peu voûtées et soupire longuement. Pourquoi s'acharner à trouver à tout prix une explication plausible pour cette fois-ci? Ça ne résoudra aucunement le pourquoi des autres nuits blanches, passées à l'attendre, à moitié morte d'inquiétude. Et immanquablement, lorsqu'il rentrera pour le dîner, il s'assoira en silence à table, comme à l'accoutumée. Elle lui servira sa soupe la main tremblante, à la fois soulagée et remplie d'amertume devant son mutisme qui lui révélera, si elle l'eut encore ignoré, le monstrueux dédain qu'elle lui inspire. Faut-il qu'il la méprise pour lui refuser ainsi la moindre excuse, le moindre mot d'explication. Comme si elle ne comptait pas pour lui... Comme si elle n'était bonne qu'à lui tremper sa soupe!

Les yeux remplis de larmes, la femme se met à pleurer, puis à sangloter. Il y a des années que ça ne lui est pas arrivé de pleurer ainsi et c'est délicieusement relaxant. La dernière fois, c'est lorsque Martine a fait cette terrible pneumonie et qu'ils sont passés si près de la perdre. Les enfants!... Cinq, plus merveilleux les uns que les autres. C'est lorsque le dernier a quitté la maison que le cauchemar a commencé. Ils se sont alors retrouvés seuls, face à face, sans rien à se dire... Plutôt que d'utiliser ces nouveaux moments d'intimité pour mieux se connaître l'un l'autre, il s'est éloigné d'elle, l'accusant silencieusement d'être responsable du vide qui grandissait autour d'eux.

Elle se mouche et tamponne ses yeux rougis. À quoi eston en droit de s'attendre lorsque deux personnes ont signé un espèce de contrat de services mutuels où les sentiments tendres sont exclus, par une mystérieuse entente dont elle ne conserve pourtant aucun souvenir. Oui, c'est bien ainsi qu'ils ont vécu ces trente années de mariage, en associés, elle, prenant soin de la maison et des enfants, lui, gagnant ce dont ils ont eu besoin pour vivre. Bien sûr, ils ont respecté leurs engagements, mais les enfants sont partis, ce contrat est, automatiquement, parvenu à terme. Trente années de vie commune pour en arriver là!

La femme se dirige vers l'évier et contemple la vaisselle entassée avec dégoût. Il lui répugne d'y tremper de nouveau 
les mains; elle connait par coeur chaque craquelure, chaque éclat enlevé au fil des ans. Et puis, ses larmes se sont si souvent mélangées à l'eau de la vaisselle...

Elle passe une main tremblante sur son visage; le sang lui martèle les tempes, symptôme annonciateur d'une de ces fâcheuses migraines qui deviennent son lot depuis quelque temps. Se dirigeant vers la salle de bain, elle prend deux comprimés dans la pharmacie, les avale, puis revient s'asseoir, désemparée. Elle jette un coup d'oeil à l'horloge et son coeur s'accélère. Le temps passe trop vite! Il lui faut songer à préparer le dîner, remettre de l'ordre avant qu'il n'arrive... Pourtant, ce matin, elle ne se sent plus le courage de faire quoi que ce soit... Et cet état de prostration l'effraie.

- Mais qu'est-ce qui me prend tout à coup?

La réponse, elle la connaît. Pourquoi continuer à refuser de regarder la réalité en face, nier l'évidence plus longtemps. À la vérité, elle n'arrive plus à "le" supporter, tout simplement. Plus! Elle le méprise, de toutes ses forces! Il lui est devenu impossible de vivre ainsi, en faisant fi de ses besoins les plus élémentaires. Le besoin d'aimer, d'être aimée, de se sentir utile à quelqu'un, devient trop fort.

Au comble d'un indescriptible malaise, la femme se met à tordre nerveusement ses mains; une étrange exaltation l'envahit.

- Je n'en peux plus! Je n'en peux plus! gémit-elle.

Les flacons reposant sur les tablettes de la pharmacie lui reviennent à l'esprit. Un moyen bien facile de se libérer du cauchemar dans lequel elle se débat depuis si longtemps, depuis trop longtemps. S'endormir pour toujours... Ne plus penser... Ne plus devoir affronter une affolante réalité... Ne plus subir cette existence inutile...

Et brusquement, son exaltation tombe. Elle repousse vite ces horribles pensées, à la fois surprise et honteuse d'avoir pu les entretenir, même un instant. 
Retournant à la salle de bain, elle s'applique une serviette d'eau froide sur la figure, évitant de se regarder dans la glace. Le visage enfoui dans le linge humide et froid, elle demeure ainsi un long moment, écoutant les battements fous de son coeur s'atténuer. Elle s'efforce alors de réfléchir calmement.

À la vérité, elle ne veut pas mourir. Bien au contraire, elle désire vivre, de toutes ses forces! Mais pas n'importe comment! Elle ne veut plus subir la vie, mais vivre la vie!...

Elle se détend un peu et boit un verre d'eau à petites gorgées. Elle se sent mieux, bien que complètement épuisée. L'impression de revenir de loin, du fond de son désespoir, n'est sans doute pas étrangère au sentiment de libération qui la remplit toute d'une énergie nouvelle. S'examinant longuement dans la glace, elle s'adresse un large sourire. son image.

- Aujourd'hui est un nouveau jour, murmure-t-elle à

Maintenant, elle sait ce qu'il lui reste à faire.

D'un pas vif, elle se dirige vers sa chambre et s'habille avec soin. Elle entreprend ensuite de faire ses valises, puis, lorsqu'elle a terminé, elle revêt son manteau, s'assied sagement face à la porte et attend. Il ne va plus tarder à présent...

Avec satisfaction, elle remarque son étonnement lorsqu'il l'aperçoit en ouvrant la porte. Pour une fois qu'il réagit à sa vue! Pourtant, il essaye encore de dissimuler; il enlève d'abord chapeau et souliers, enfile ses pantoufles avant de demander, d'une voix la plus indifférente possible:

- Qu'est-ce que tu fais là?

Elle n'est pas sans ignorer que rien de ce qui se passe ne lui a échappé, depuis le désordre de la maison jusqu'à ses valises. Malgré tout, il continue à feindre l'indifférence, à jouer les inattaquables. Mais à quel jeu s'amuse-t-il donc? 
- J'attendais ton retour.

Malicieusement, elle attend qu'il parle. Quelques secondes passent dans un silence lourd.

- Avec ton manteau et tes valises? questionne-t-il enfin.

- J'attendais ton retour pour t'annoncer mon départ.

Il fait mine de se désintéresser d'elle et se dirige vers la cuisine d'un pas mesuré.

- Le dîner n'est pas prêt?

- Je pars, répète-t-elle doucement.

Cette fois-ci, il se fâche pour de bon:

- Qu'est-ce que c'est que cette histoire? Où vas-tu?

- Chez Clothilde.

Il la dévisage, l'air furieux. Toronto!

- Tu es complètement folle! Chez Clothilde! Elle habite - Je sais...

Il s'apaise soudain. Une pensée lui vient tout à coup:

- Elle est morte? questionne-t-il.

- Mais non, elle va très bien!

- Mais alors! Qu'est-ce que c'est que cette histoire de voyage?

Sa voix résonne de façon étrange. Elel constate avec surprise qu'il commence à avoir peur. 
- J'ai pris la décision d'aller rejoindre ma soeur. Elle me le demande depuis si longtemps.

- Tu as pris la décision?

Il la considère les yeux ronds. L'idée qu'elle soit capable de prendre une décision ne lui a sans doute jamais effleuré l'esprit.

- Et moi? fait-il.

- Toi?

Elle se lève et plonge son regard dans le sien:

- Toi, tu n'as pas besoin de moi! Tu n'as sans doute jamais eu besoin de moi!...

Elle le voit troubler réellement.

- Qu'est-ce que tu as aujourd'hui? fait-il d'une voix sourde. On dirait...

Il n'arrive pas à trouver les mots pour expliquer ce qu'il ressent. Presqu'intimidé, il regarde cette femme debout devant lui, redressée de toute sa petite taille, l'air de le défier... Et c'est vraiment comme s'il la voyait pour la première fois. Il la trouve, tout à coup, si... différente!

- On dirait que tu n'es plus la même aujourd'hui... Qu'est-ce qui se passe?... Qu'est-ce que tu as?... valises.

Comme elle ne répond pas, il jette un coup d'oeil aux

- Quand vas-tu revenir?

- Je ne sais pas Peut-être jamais...

- Qu'est-ce que tu dis? rugit-il, la figure empourprée. 
La femme soutient son regard menaçant sans broncher. Est-il ridicule de croire qu'il peut encore la terrifier! Émerveillée de sa toute nouvelle détermination, elle riposte: toute façon.

- Inutile de te mettre en colère. Ça ne changera rien de

Décidée à ne pas prolonger plus longtemps cette scène pénible, elle saisit ses valises et se dirige vers la porte.

- Pourquoi? fait la voix de son mari dans son dos.

Il la considère, l'air hagard. quoi?

- Pourquoi; répète-t-elle. Tu ne sais vraiment pas pour-

Il ouvre la bouche pour répliquer mais ne trouve rien à dire. Il baisse la tête, vaincu.

Elle dépose ses valises et met la main sur la poignée de la porte.

- Et les enfants? s'exclame-t-il d'une voix rauque.

Prétexte ultime, sans doute pour gagner du temps. retourner.

- Je vais leur écrire de là-bas, réplique-t-elle sans se

Le bruit étouffé d'un sanglot, puis la voix de son mari lui parvient, méconnaissable:

- Reste!... Ne pars pas!...

Un long frémissement la parcourt de la tête aux pieds. Elle demeure un moment immobile, le coeur chaviré. Il pleure! Jamais encore elle ne l'a vu pleurer. Son habituelle façon de la traiter avec arrogance et mépris l'a intimement persuadée de ne représenter à ses yeux qu'un poids, un fardeau inutile et nuisible, dont on a surtout envie de se débarrasser. 
Il s'est donné tant de mal pour l'en convaincre. Et de penser qu'il tient cependant à elle, la remplit d'un curieux mélange de rancune, de joie et d'étonnement, la laissant douloureusement hésitante. La main crispée sur la poignée de la porte, elle reste figée, incapable de réagir.

Pourtant sa décision de partir est la plus forte. Il le faut! C'est aujourd'hui ou jamais! Si elle reste maintenant, elle perd la partie. Elle ne pourra plus retrouver le courage de recommencer.

Elle reprend vite son aplomb.

- Au revoir, fait-elle en refermant doucement la porte.

Écrasant furtivement une larme, elle s'éloigne d'un pas assuré, sachant que c'est l'unique chose à faire, aussi bien pour elle, que pour eux. 